\title{
Secondary Perineal Hernia Perforation Post Trauma
}

\author{
${ }^{1}$ Emergency and Trauma Surgery, Pontifícia Universidade Católica de Campinas/ \\ PUC Campinas, Brazil \\ ${ }^{2}$ Medicine Student, Pontifícia Universidade Católica de Campinas/PUC Campinas, \\ Brazil \\ ${ }^{3}$ Coloproctology service, Clínica Reis Neto, Brazil \\ *Corresponding Author: Md Hugo Samartine Júnior, Emergency and Trauma \\ Surgery, Pontifícia Universidade Católica de Campinas/PUC Campinas, Brazil.
}

\section{Md Hugo Samartine Júnior ${ }^{1 *}$, Lauro Igor Silva², Giovanna Bertazzola \\ Gracitelli $^{2}$, Md Mariana Gonçalves Marangon ${ }^{1}$, Md Ariane Caetano Hardy $^{1}$, Md Sergio Oliva Banci ${ }^{1,3}$, Antonio José Tibúrcio Alves Júnior ${ }^{1,3}$ and José Alfredo Reis Neto ${ }^{3}$}

Received: December 06, 2021

Published: December 29, 2021

(C) All rights are reserved by Md Hugo

Samartine Júnior., et al.

\begin{abstract}
Perineal Hernias (PH) result from weakness or defects in the pelvic floor musculature, which may allow the passage of abdominal contents to a pelvic-perineal region. They can be classified as primary (congenital) or secondary (post-pelvic surgery), being anatomically distinguished by their position, anterior or posterior, to the transverse perineal muscle. With variable clinical presentation and surgical treatment aimed at cases with greater symptoms, complications caused by perineal hernias in outpatient follow-up are rarely described in the literature. The objective of this study is to carry out a brief literature review and report a case of perineal hernia in a conservative clinical-surgical follow-up, with a perforation event after trauma, approached in an emergency room.
\end{abstract}

Keywords: Pelvic Floor; Abdominoperineal Surgery; Perineal Hernia; Intestinal Perforation

\section{Abbreviation \\ PH: Perineal Hernias}

\section{Introduction}

Perineal hernias (PH) result from weaknesses or defects in the pelvic floor muscles, capable of allowing the passage of abdominal contents to the pelvic-perineal region [1,2]. Perineal hernias $\mathrm{PH})$ result from weakness or defects in the pelvic floor muscu- lature, capable of allowing the passage of abdominal contents to the pelvic-perineal region [1,2]. They can be classified as primary, taking as an example the congenital entities, being quite rare entities, or secondary, resulting from the fragility generated after a pelvic surgical procedure, such as abdominoperineal amputation or pelvic exenteration [3]. It is a non-common pathological alteration, being anatomically distinguished by its position, anterior or posterior to the transverse perineal muscle [1,4,5]. With variable clinical features and surgical treatment aimed at cases of greater 
symptomatology, complications caused by perineal hernia in outpatient follow-up are rarely ruled out in literature.

The objective of this study is to carry out a brief review of the literature and report a case of perineal hernia in clinical follow-up, with a post-trauma perforation event, approached in an emergency.

\section{Case Report}

LAV, 67 years old, male, in perineal hernia follow-up at Hospital PUC Campinas, after abdominoperineal amputation due to advanced low rectal adenocarcinoma, diagnosed in 2014, followed by neoadjuvant therapy and surgical treatment, and also in follow-up by synchronous prostate cancer, undergoing palliative chemotherapy due to bone metastasis since the same period.

He was seen in the Emergency Room of our service after syncope followed by a fall from his own height, with severe abdominal and pelvic pain, associated with nausea and vomiting, and, on physical examination, incarcerated moderate perineal hernia with local phlogistic signs.

Having ruled out any seriousness that could be related to the neurological condition, and being hemodynamically stable, he was initially submitted to computed tomography, which showed a massive herniation of small bowel loops and colon in the perineal region (Figure 1), with an approximate ostium of $4.2 \mathrm{~cm}$. Along with the hernia content, there was evidence of a moderate amount of free intraperitoneal fluid associated with spots of pneumoperitoneum, suggestive of intestinal perforation (Figure 2).

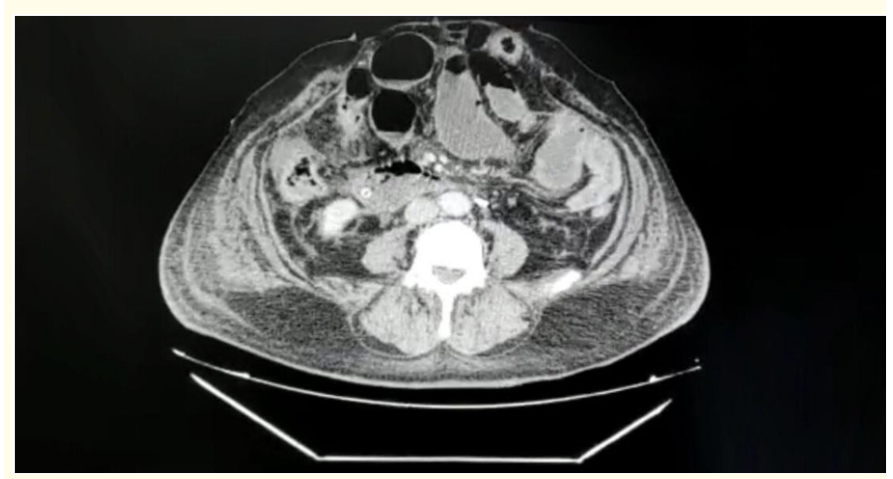

Figure 1: Perineal hernia content.

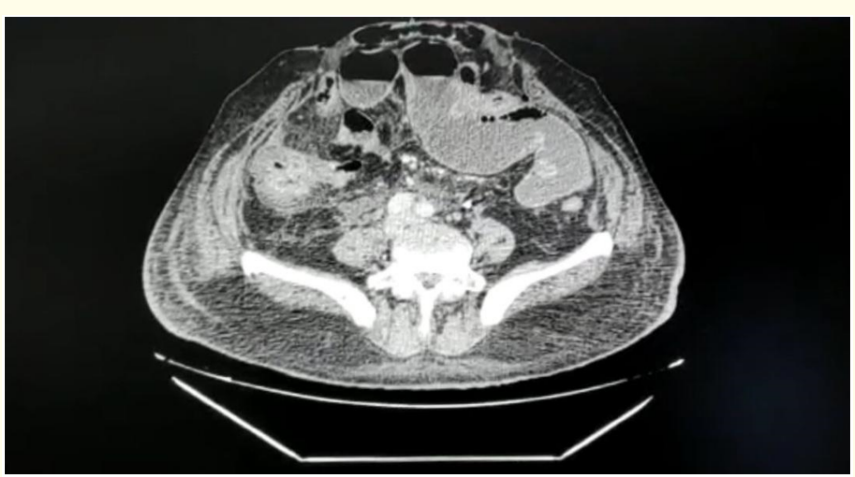

Figure 2: Intestinal perforation findings (free liquid and pneumoperitoneum spots).

Referred to emergency surgery, with intraoperative isolated laceration in the small intestine, approximately $3 \mathrm{~cm}$ long, at 90 $\mathrm{cm}$ from the angle of Treitz (Figures 3 and 4), with diagnostic confirmation and the need for intestinal surgical approach and hernia repair.

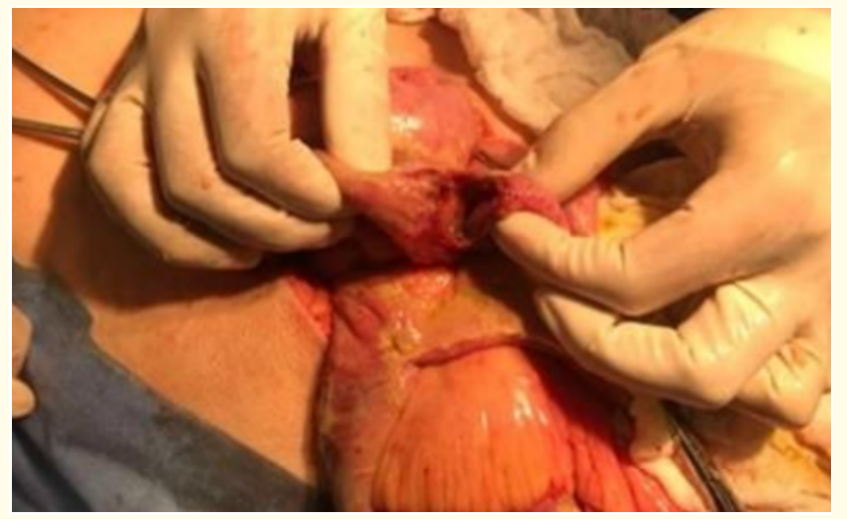

Figure 3: Small intestine laceration.

A revival of the edges was performed with closure in two planes, followed by irrigation of the abdominal cavity and, at the same surgical time, hernia correction by primary closure of the pelvic wall. Opted for peritonectomy with plastic film to shorten the surgical time. 


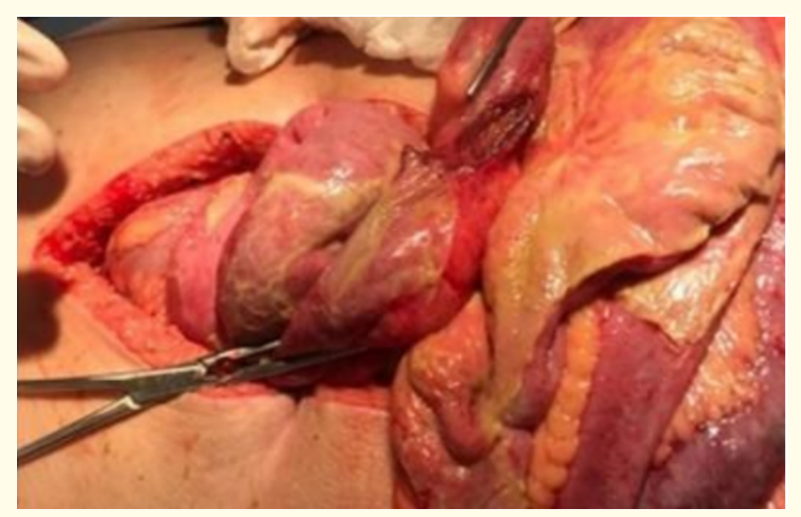

Figure 4: Intestinal edges revival for later closing in two plans.

Two subsequent posterior surgical approaches were performed to review the cavity, without complications and without evidence of hernia recurrence. During hospitalization, the patient evolved with cardiopulmonary complications, refractory to clinical treatment, evolving to death.

\section{Results and Discussion}

PH was first described in 1939 by Yeomans [6], after a rectal cancer resection, having a first report in the laparoscopy era in 2007, by Veenhof., et al. [7].

The incidence of symptomatic PH secondary to abdominoperineal surgeries has been presented in 0.626 to $1 \%$ of cases [8-10], most of which are evidenced after one year of surgery. They affect patients between the fifth and seventh decades of life, especially women, in a ratio of 5:1, having as risk factors diabetes mellitus, obesity, patients undergoing neoadjuvant therapy [11,12] and postoperative wound infections [13].

In general, $\mathrm{PH}$ are asymptomatic, which contributes to the low incidence of this disease in the literature [4]. In the presence of symptoms, the clinical picture can be characterized by perineal discomfort when sitting, feeling of perineal heaviness, skin laceration, urinary symptoms and intestinal obstruction [2], among others, and the diagnosis is usually established in the clinical history and physical examination.

Occasionally, for diagnostic complementation, imaging exams such as contrast radiography, computed tomography or magnetic resonance imaging are necessary, differentiating with lipomas, fibromas, rectocele, cystocele and prolapsed rectum [14-16].

The treatment is surgical, indicated for patients who develop symptoms such as skin erosion, discomfort, pain, bowel obstruction or urinary obstruction, or in congenital cases [2]. However, elderly patients, patients with severe comorbidities, and those with few symptoms may experience relief from symptoms only with the use of local bandages, and corrective surgery is not necessary. If surgery is chosen, it can be performed perineally, abdominally, laparoscopically or mixed, and the repair of this type of defect is still presented today as a surgical challenge in which several methods have been described, without an established ideal approach $[9,17]$.

In the literature, complications caused by $\mathrm{PH}$ are not well described. An extensive search in databases such as SciELO, SCOPUS, PubMed, revealed only one other case of traumatic perforation, in a patient with diagnosed PH, described in 2018 by Ugwu., et al. [17], with a female patient, the most common incidence of the underlying condition, which, after pelvic trauma to $\mathrm{PH}$, also evolved with perforating acute abdomen [18].

In the case reported here, the patient presented as the main risk factor for PH a cancer history and neoadjuvant therapy, in addition to a prolonged cancer status with the diagnosis of a second synchronous tumor and palliative chemotherapy. Added to the poor symptoms, it resulted in factors that motivated outpatient conservative treatment.

In view of the situation of intestinal perforation, the approach adopted was the abdominal route, in urgent circumstances, contamination of the cavity and the need for an intestinal approach and exhaustive washing of the cavity.

In the literature, preventive measures are described in abdominoperineal amputation procedures, including primary closure being almost always possible in the classic intersphincteric technique, while in the extra-levator excision and in the ischioanal technique, additional measures of pelvic floor reconstruction are needed, either by omentoplasty with a large epiplon flap, uterine flap repair, musculocutaneous flaps with rectus abdominis, large gluteus or gracilis and the placement of biological collagen prostheses $[19,20]$. However, just as the repair of this type of defect remains a surgical challenge, its prevention method also remains without an established consensus. 
As it may have variable symptoms and associated severe complications, $\mathrm{PH}$ is capable of representing a diagnostic challenge for surgeons who have not been exposed to this unusual entity.

Consideration of risk factors and possible complications requires better surgical design and planning methods for prevention techniques. Therefore, the importance of diagnosing and disseminating information about this condition is precisely to be able to discuss the risk factors, possible complications and the possibilities of correcting this pelvic fragility, in the post-surgical period of pelvic surgeries, such as abdominoperineal amputation or pelvic exenteration, minimizing the possibility of forming a perineal hernia.

\section{Conclusion}

PH are possible complications of abdominoperineal amputation of the rectum that have been described and may present with variable symptoms and associated severe complications, capable of representing a diagnostic challenge for surgeons who have not been exposed to this atypical entity. Thinking about the importance of diagnosis, risk factors, and possible complications requires planning methods for better surgical design and preventive techniques.

Therefore, the surgeon must be prepared to deal with this situation, which can present itself with a high degree of severity.

\section{Conflict of Interest}

We declare that there is no financial interest or conflict of interest.

\section{Bibliography}

1. Lubat E., et al. "CT Diagnosis of Posterior Perineal Hernia". American Journal of Roentgenology 154.4 (1990): 761-762.

2. Ntaganda Edmond., et al. "Congenital Perineal Hernia”. Journal of Pediatric Surgery Case Reports 32 (2018): 46-48.

3. Perin Ramir Luan., et al. "Correção de hérnia perineal com colocação de tela por videolaparoscopia”. Journal of Coloproctology 38 (2018): 187.

4. Thomford Neil R and Neil J Sherman. "Primary perineal hernia". Diseases of the Colon and Rectum 12.6 (1969): 441-443.

5. Mandarano R., et al. "[Perineal hernia]". Minerva Chirurgica 54.7-8 (1999): 523-529.
6. Yeomans,Frank C. "Levator Hernia, Perineal and Pudendal". The American Journal of Surgery 43.3 (1939): 695-697.

7. Veenhof Alexander A F A., et al. "Perineal Hernia After Laparoscopic Abdominoperineal Resection for Rectal Cancer: Report of Two Cases". Diseases of the Colon and Rectum 50.8 (2007): 1271-1274.

8. Cruz, Geraldo Magela Gomes da., et al. "Estudo retrospectivo de 47 complicações em 380 pacientes operados de câncer retal". Revista Brasileira de Coloproctologia 26, Cidade Editora Científica Ltda (2006): 138-155.

9. Beck, David E., et al. "Postoperative Perineal Hernia”. Diseases of the Colon and Rectum 30.1 (1987): 21-24.

10. Sarr MG., et al. "Combined Abdominoperineal Approach to Repair of Postoperative Perineal Hernia". Diseases of the Colon and Rectum 25.6 (1982): 597-599.

11. Bullard Kelli M., et al. "Primary Perineal Wound Closure After Preoperative Radiotherapy and Abdominoperineal Resection Has a High Incidence of Wound Failure". Diseases of the Colon and Rectum 48.3 (2005): 438-443.

12. Wes N P., et al. "Multicentre Experience with Extralevator Abdominoperineal Excision for Low Rectal Cancer". British Journal of Surgery 97.4 (2010): 588-599.

13. Ewan Lc., et al. "Two Case Reports of Perineal Hernia after Laparoscopic Abdominoperineal Resection with a Proposed Modification to the Operative Technique". The Annals of The Royal College of Surgeons of England 96.2 (2014): e9-10.

14. Rajabaleyan Pooya., et al. "Robot-Assisted Laparoscopic Repair of Perineal Hernia after Abdominoperineal Resection: A Case Report and Review of the Literature". International Journal of Surgery Case Reports 55 (2019): 54-57.

15. Ryan Stephen., et al. "Laparoscopic Repair of Postoperative Perineal Hernia". Case Reports in Medicine (2010): e126483.

16. Dulucq J L., et al. "Laparoscopic Repair of Postoperative Perineal Hernia". Surgical Endoscopy And Other Interventional Techniques 20.3 (2006): 414-418.

17. So Jimmy Bok -yan., et al. "Postoperative Perineal Hernia”. Diseases of the Colon and Rectum 40.8 (1997): 954-957. 
18. Ugwu Ajogwu U., et al. "Traumatic Small Bowel Perforation in a Case of a Perineal Hernia". Journal of Surgical Case Reports (2018): rjy330.

19. Butt Hisham Z., et al. "Perineal Reconstruction after Extra-Levator Abdominoperineal Excision (ELAPE): A Systematic Review". International Journal of Colorectal Disease 28.11 (2013): 1459-1468.

20. Musters Gijsbert D., et al. "Randomized Controlled Multicentre Study Comparing Biological Mesh Closure of the Pelvic Floor with Primary Perineal Wound Closure after Extralevator Abdominoperineal Resection for Rectal Cancer (BIOPEX-Study)". BMC Surgery 14.1 (2014): 58.

\section{Assets from publication with us}

- Prompt Acknowledgement after receiving the article

- Thorough Double blinded peer review

- Rapid Publication

- Issue of Publication Certificate

- High visibility of your Published work

Website: www.actascientific.com/

Submit Article: www.actascientific.com/submission.php

Email us: editor@actascientific.com

Contact us: +919182824667 